\title{
Current and Future Developments of PARP Inhibitors in the Treatment of Breast and Ovarian Cancer
}

Dieuwke Luijten ${ }^{1}$, Maaike PG Vreeswijk², Ingrid Boere ${ }^{3}$ and Judith R Kroep ${ }^{1 *}$

${ }^{1}$ Department of Medical Oncology, Leiden University Medical Center, Albinusdreef, Netherlands

${ }^{2}$ Department of Human Genetics, Leiden University Medical Center, Albinusdreef, Netherlands

${ }^{3}$ Department of Medical Oncology, Erasmus MC Cancer Institute, Rotterdam, Netherlands

\begin{abstract}
The use of Poly ADP-ribose polymerase (PARP) inhibitors has recently been expanded. PARP inhibitors were initially only registered for patients with BRCA mutated high-grade serous epithelial ovarian, including primary peritoneal and fallopian tube cancer (EOC). Currently, PARP inhibitors are also registered for patients with recurrent $\mathrm{EOC}$ who are in a complete or partial response to platinum-based chemotherapy, irrespective of their BRCA status. Current findings indicate that patients with BRCA mutations and/or a BRCA like tumour defined by a BRCAness profile, benefit the most. Combination therapies of PARP inhibitors with immunotherapy and/or angiogenesis inhibitors are fast evolving and studied from first line therapy to recurrent disease. This review summarizes the current findings, obstacles and future developments of PARP inhibitor with a focus on female cancer.
\end{abstract}

Keywords: Breast cancer; Ovarian cancer; BRCA1; BRCA2; PARP inhibitors; Homology-directed repair deficiency

\section{Introduction}

Loss of function germline mutations in BRCA1 and BRCA2 increase the risk of breast and ovarian cancers and have been associated with increased risks of several additional types of cancer. The cumulative breast cancer risk till 80 years is $72 \%$ for BRCA1 and $69 \%$ for BRCA2 carriers [1]. The cumulative ovarian cancer risk, including primary peritoneal and fallopian tube cancer (EOC) till 80 years is $44 \%$ for BRCA1 and $17 \%$ for BRCA2 carriers [1].

In 2005, the first two publications demonstrating the substantial sensitivity of BRCA deficient cell lines to inhibition of PARP, have led to an unprecedented and swift implementation of PARP inhibitors in clinical practice $[2,3]$. Several PARP inhibitors such as olaparib, niraparib, veliparib, rucaparib, and talazoparib are being tested in clinical trials and olaparib, niraparib and rucaparib have been registered for use in a clinical setting.

Current challenges include the selection of patients who benefit most from PARP inhibition, selecting optimal use of PARP inhibitors as monotherapy, maintenance or combination therapy and the occurrence of drug resistance. This review summarizes the proceedings and discusses the future developments of PARP inhibitors with focus on its use in patients with breast and ovarian cancer.

\section{Literature Review}

\section{DNA damage response}

DNA breaks can be roughly divided in two groups: single strand breaks (SSBs) and double-strand breaks (DSBs). SSBs can be accurately repaired using the other strand as a template, a process in which the enzyme Poly (ADP-ribose) polymerases (PARP) is involved. DSBs can be induced by radiation or X-rays, free radicals, chemicals and during replication of SSBs [4]. DSBs are mainly repaired through two pathways: the homology-directed repair (HDR) pathway and the nonhomologous end joining (NHEJ) pathway, although other mechanisms also exist $[4,5]$. The HDR pathway has very few errors and duplicates the DNA using the homologous sequence of the sister chromatid as a template to repair the DSB. HDR takes place during S and G2 cell cycle phase. The NHEJ pathway is more error prone, which may lead to alterations in DNA sequence and loss of genetic information $[4,6]$.

BRCA1 and BRCA2 are involved in the DNA damage response, the network of interacting pathways that are essential for the response upon DNA damage. Both proteins are involved in the error-free repair of DSBs by HDR [4]. BRCA1 signals DNA damage and ensures cell cycle regulation [6], while BRCA2 interacts and facilitates the loading and formation of RAD51 filaments on the damaged DNA strand [7]. In the presence of loss of function mutations in either of these genes (e.g. in BRCA1 or BRCA2 mutated tumours), HDR is deficient, DSBs will be repaired via error prone repair pathways leading to the accumulation of mutations, eventually resulting in cell death [8]. This may ultimately lead to enhanced risk for breast and ovarian cancer.

\section{PARP inhibitors: Mechanism of action and synthetic lethality}

Poly (ADP-ribose) polymerases (PARPs) regulate a number of biological processes [9]. PARP-1 is part of the PARP protein family and is involved in base excision repair (BER). DNA modifications, either induced endogenously or exogenously, can be repaired by BER. After excision of the damaged base, an SSB is produced [9]. Normally, PARP1 binds to the SSB and attracts other proteins to initiate SSB repair [10]. Initially, it was proposed that inhibition of PARP-1 would lead to stalling of the replication fork at the SSB [11], leading to accumulation of double strand breaks (DSBs) in replicating cells. However, recent data suggest that some PARP inhibitors might also 'trap' PARP1 on the DNA and thereby interfere with the catalytic cycle of PARP [12] (Figure 1). The ability of PARP inhibitors to trap PARP1 on DNA has been shown to add to the observed cytotoxicity [13]. More recent data suggest that PARP also has a function in the repair of DSBs [5].

*Corresponding author: Judith R Kroep, Department of Medical Oncology, Leiden University Medical Center, Albinusdreef 2, 2333ZA, Netherlands, Tel: +31 71526 9111; E-mail: j.r.kroep@lumc.n

Received May 23, 2018; Accepted July 23, 2018; Published July 25, 2018

Citation: Luijten D, Vreeswijk MPG, Boere I, Kroep JR (2018) Current and Future Developments of PARP Inhibitors in the Treatment of Breast and Ovarian Cancer. $J$ Cancer Sci Ther 10: 178-189. doi: 10.4172/1948-5956.1000542

Copyright: (C) 2018 Luijten D, et al. This is an open-access article distributed under the terms of the Creative Commons Attribution License, which permits unrestricted use, distribution, and reproduction in any medium, provided the original author and source are credited. 

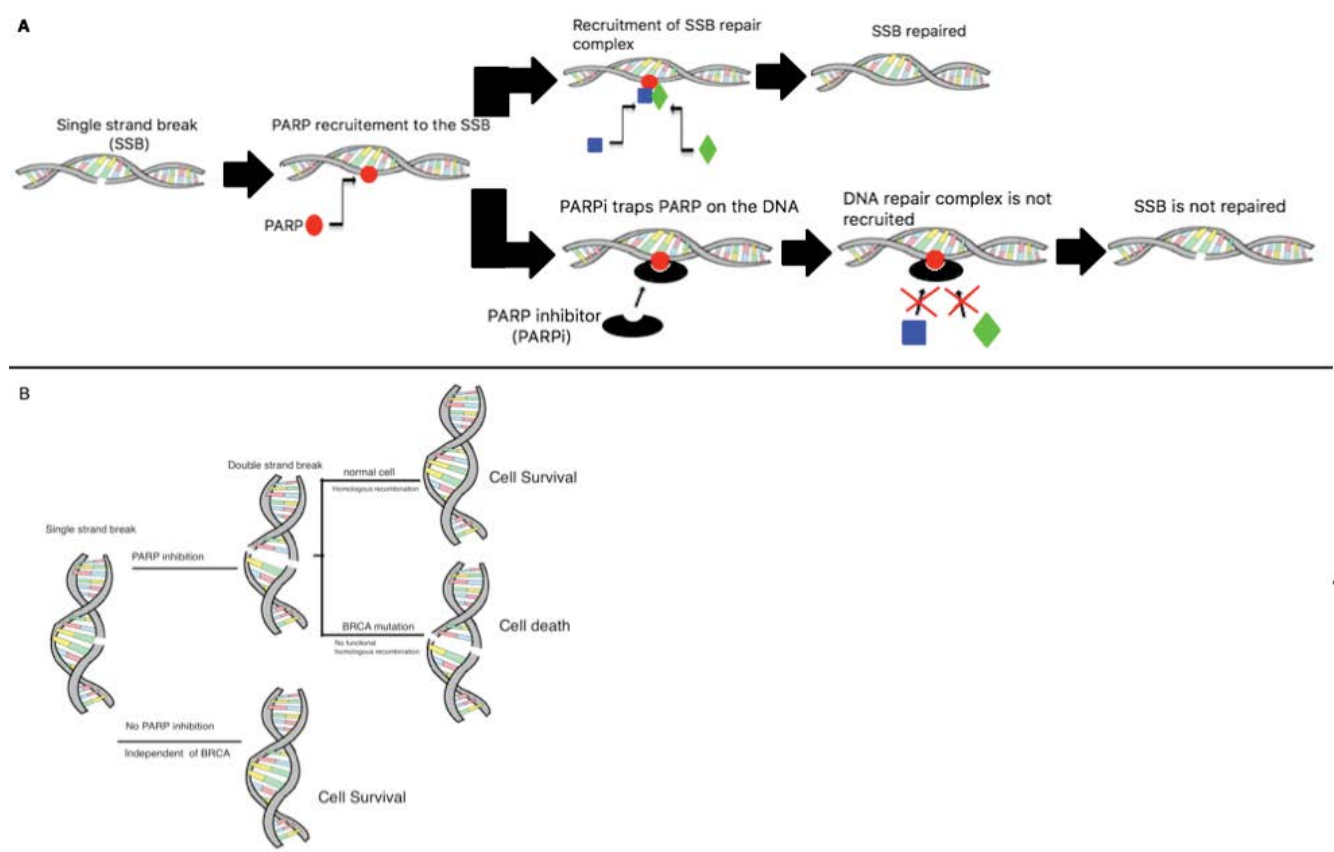

Figure 1: Mechanism of PARP inhibition based on synthetic lethality (A): When an SSB is present in the DNA, PARP will be recruited to the SSB site. PARP recruits a complex to perform SSB repair. In the presence of PARP inhibitors parylation is inhibited and PARP1 is trapped on the DNA and the SSB will not be repaired. (adapted from Livraghi and Garber [14]) (B): In the presence of PARP, SSBs will be repaired. However, in the presence of PARP inhibitors, SSBs will not be repaired what will result replication fork stalling, which eventually may collapse and result in DSBs. DSBs can be repaired through HDR which will result in cell survival. However, in HDR deficient tumours (e.g. in BRCA1 or BRCA2 mutated tumours), the error free repair of DSBs fails, which will ultimately lead to tumour cell death.

The effectiveness of PARP inhibitors in tumours related to BRCA1 and BRCA2 is based on the concept of synthetic lethality, whereby a deficiency in either one of two genes has no effect on the viability of the cell but the combination of defects in both genes will result in cell death (described in detail in several reviews $[12,14]$ ).

Thus, especially in BRCA deficient and HDR deficient cells, inhibition of PARP enzyme will lead to cell death (Figure 1). Normal cells have a sufficient HDR function and will therefore survive PARP inhibitor therapy. This leads to in a more precise and less toxic therapy compered to chemotherapy [14]. Therefore, PARP inhibitors are potent drugs, particularly in BRCA mutated types of cancer and other HDR deficient malignancies [15].

\section{Clinical Development of PARP Inhibitors}

Currently many PARP inhibitors are in clinical trials as monotherapy and/or as combination therapy. First, the European Medical Association (EMA) and the Food and Drug Administration (FDA) registered olaparib as maintenance therapy of platinum-sensitive relapsed germline BRCA mutated (gBRCAm) high-grade serous EOC that responded to platinum-based chemotherapy [16,17]. Recently, olaparib tablets were registered recently by the EMA irrespective of BRCA status [16]. The FDA also registered olaparib as monotherapy for treating patients with gBRCAm recurrent EOC after receiving three or more prior lines of chemotherapy [17]. Moreover, the FDA also registered olaparib for the treatment of patients with gBRCAm, HER2negative metastatic breast cancer who have previously been treated with chemotherapy [16]. Rucaparib was registered by the FDA in 2016 as monotherapy for the treatment of patients with BRCA mutated recurrent EOC who have received two or more chemotherapies [18] and in 2018 rucaparib was registered as maintenance treatment for patients with recurrent EOC who are in complete or partial response to platinum-based chemotherapy [19]. Niraparib, was registered in 2017 as maintenance treatment for adult patients with recurrent platinumsensitive EOC who are in a complete or partial response to platinumbased chemotherapy irrespective of BRCA status of the tumor [20]. Recently, the EMA also granted registration of niraparib for the same indication [21].

\section{Olaparib (AstraZeneca)}

One of the most investigated PARP inhibitors is olaparib. [22] was the first to investigate pharmacokinetics and pharmacodynamics in patients with, among others, breast and ovarian cancer. Of the 60 patients enrolled, 22 had a BRCA1 or BRCA2 germline mutation. Results revealed a maximum tolerated dose (MTD) of $400 \mathrm{mg}$ BID olaparib capsules. Adverse events were mainly grade 1-2 and included vomiting, taste alteration, nausea, fatigue and anorexia. Subsequent phase II trials in patients with a gBRCAm, revealed an overall response rate (ORR) of $41 \%$ in patients with advanced breast cancer [23] and of $33 \%$ in recurrent EOC [24,25] showed a tumour response rate in metastatic breast cancer patients with $\geq 3$ chemotherapy regimens of $12.9 \%$ (95\% CI, 5.7 to 23.9). For platinum resistant relapsed EOC, the ORR was 31.1\% (95\% CI, 24.6 to 38.1). Based on these promising results, a subsequent trial (study 19) was initiated by Ledermann et al. [26]. This phase II trial compared the efficacy of olaparib to placebo as maintenance therapy after response to platinum-based chemotherapy in 265 patients with platinum-sensitive recurrent serous EOC. Overall results showed that olaparib increased median progression free survival (PFS) when compared to placebo ( 8.4 months vs 4.8 months respectively; HR $0.35 ; \mathrm{p}<000.1$ ) [26]. The subgroup analysis by overall BRCA mutation (BRCAm) status (germline and somatic) showed a significant benefit in median PFS in the olaparib group compared to the placebo group (11.2 vs 4.3 months respectively; HR 0.18; $<<0.0001)$ 
[27]. Adverse events were mostly grade 1-2. This study led to the EMA and FDA registration of olaparib for EOC $[16,17]$.

However, despite a large difference in PFS, there was no benefit shown in overall survival (OS) [26,27]. Nonetheless, [28] did an exploratory post hoc analysis to investigate if OS was confounded due to switching to a PARP inhibitor after progression by $23 \%$ of the patients receiving placebo. They concluded that post progression PARP inhibitor therapy had a confounding influence on the OS analyse and therefore patients with BRCA mutated recurrent EOC treated with olaparib might actually have longer OS. The phase III SOLO2/ENGOTOv21 trial, investigated the efficacy of olaparib maintenance therapy in platinum-sensitive recurrent EOC. They confirmed the findings from Study 19 in the BRCA1/2 mutation subgroup using the olaparib tablet, $300 \mathrm{mg}$ BID, formulation [29]. Furthermore, the SOLO-1 trial [30] is currently investigating the efficacy of olaparib maintenance therapy compared to placebo in primary BRCAm EOC after first line platinumbased chemotherapy. Olaparib is also investigated in breast cancer both in metastatic and adjuvant settings in the OlympiA [31] and OlympiAD [32] trial, respectively. Presented data from the OlympiAD trial showed that patients treated with olaparib had a $42 \%$ risk reduction of disease worsening or death as compared to standard chemotherapy (HR 0.58; $\mathrm{p}=0.0009$ ) [33]. Based on these results olaparib was registered by the FDA for the treatment of patients with gBRCAm, HER2-negative metastatic breast cancer who have previously been treated with chemotherapy [17].

\section{Veliparib (Abbvie)}

Veliparib is another PARP inhibitor of which clinical trials show promising results in recurrent EOC. The first phase I trial by Puhalla et al. [34] recommended a phase 2 dose (RP2D) of $400 \mathrm{mg}$ BID for the treatment of platinum-resistant or -refractory EOC or basal-like breast cancer. 60 out of 88 patients had a gBRCAm. Nausea, fatigue, and lymphopenia were the most common all-grade toxicities. In the phase II study by Coleman et al. [35] veliparib monotherapy was administered in 50 patients with persistent or recurrent EOC carrying a BRCAm. Results showed an ORR of $26 \%$ with acceptable toxicity. No data on OS with veliparib are available yet.

\section{Niraparib (Tesaro)}

Another potent PARP inhibitor is niraparib. This PARP inhibitor was first clinically tested in the phase I trial by Sandhu et al. [36] The RP2D was $300 \mathrm{mg} /$ day with adverse events of anaemia, anorexia, fatigue, neutropenia, nausea, thrombocytopenia, constipation and vomiting (mostly grade 1-2). Efficacy evaluation revealed that $40 \%$ of patients with BRCAm recurrent EOC and $50 \%$ of patients with metastatic breast cancer had a partial response. Recently, the placebocontrolled phase III NOVA trial [37], with niraparib as maintenance therapy after completing or near complete response to platinum-based chemotherapy in patients with platinum-sensitive recurrent EOC, revealed a higher PFS in the niraparib group than in the placebo group. Patients with a gBRCAm had the largest benefit with an increase in PFS of 21.0 vs. 5.5 months (HR: 0.27), followed by a subgroup with HDR deficiency as defined by the MyChoice HDR deficiency test (Myriad Genetics) (see section 6) with an increase in PFS of 12.9 vs 3.8 months (HR: 0.38). Surprisingly, even in the HDR proficient group a PFS benefit of 6.9 vs 3.8 months was observed (HR: 0.58). OS data were not mature. It was concluded that niraparib is beneficial in all patients with platinum-sensitive recurrent EOC in response to platinum-based chemotherapy regardless of the BRCA mutation or HDR deficiency status. Furthermore, [38] concluded that patients treated with niraparib after complete or partial response can maintain their quality of life.

Because of these results, the FDA and EMA have accepted niraparib for the treatment of platinum-sensitive recurrent EOC irrespective of BRCA status [20,21]. For patients with anthracycline and taxanes resistant metastatic breast cancer the efficacy of niraparib monotherapy is currently being tested in the BRAVO trial (NCT01905592) [39]. Moreover, the efficacy of niraparib maintenance therapy for patients with primary EOC after first line platinum-based chemotherapy is investigated in the ongoing PRIMA trial [40].

\section{Rucaparib (Clovis oncology)}

One of the first phase I trials investigating rucaparib was done by Kristeleit et al. [41]. Results showed a RP2D of $600 \mathrm{mg}$ BID [42] subsequently investigated the efficacy of intravenous (IV) intermittent and oral continuous dosing schedules of rucaparib in gBRCAm recurrent ovarian and metastatic breast cancer. The IV intermittent dosing schedule resulted in an ORR of $2 \%$, which was $15 \%$ for oral rucaparib. $41 \%$ of the patients receiving the IV intermittent dosing schedule achieved stable disease (SD) for $\geq 12$ weeks. In the oral continuous dosing cohort $81 \%$ achieved RECIST complete response, partial response or SD for $\geq 12$ weeks. They concluded that oral continuous rucaparib dosing is required for best results. Furthermore, the ARIEL2 trial investigated the efficacy of rucaparib in 3 groups with relapsed EOC; patients with a BRCA mutation, patients with high loss of heterozygosity ( $\mathrm{LOH}$ ) as a definition for HDR deficiency and patients with low LOH [43]. Results showed a median PFS of 12.8 , 5.7 and 5.2 months, respectively. PFS was significantly higher in the BRCAm (HR: $0.27 \mathrm{p}<0.001)$ and LOH high group (HR:0.62, $\mathrm{p}=0.011)$ compared to the LOH low group.

Finally, the ARIEL3 trial investigated the efficacy of rucaparib maintenance treatment for recurrent EOC after response to platinumbased chemotherapy [44]. For BRCAm patients this phase III trial showed a median PFS of 16.6 months in the rucaparib group compared to 5.4 months in the placebo group (HR:0.23; $<<0.0001$ ). For patients with a HDR deficiency (defined as high LOH) EOC the median PFS was 13.6 months in the rucaparib group versus 5.4 months in the placebo group (HR:0.32; $\mathrm{p}<0.0001$ ).

Based on these results rucaparib was registered in 2016 as monotherapy for the treatment of patients with BRCAm recurrent EOC who have received two or more lines of chemotherapy [18] and in 2018 rucaparib was registered as maintenance treatment for patients with recurrent EOC who are in complete or partial response to platinumbased chemotherapy [19].

\section{Combination Therapy}

\section{Chemotherapy and PARP inhibitors}

Olaparib in combination with chemotherapy: In order to achieve synergy and improve clinical efficacy, PARP inhibitors have been combined with chemotherapy. However, this combination is challenging due to overlapping bone marrow toxicity. [45] designed a phase I trial to determine the safety of olaparib plus cisplatin in patients with advanced breast cancer, EOC and other solid tumours. The MTD could not be established because none of the cohorts reached dose-limiting toxicity and therefore the authors concluded that the scheme of cisplatin $60 \mathrm{mg} / \mathrm{m}^{2}$ (day 1, q21 days) in combination with intermittent $50 \mathrm{mg}$ olaparib capsules (days 1-5) was tolerable. Subsequently, Oza [46] investigated, in a randomized phase II trial, the combination of olaparib (200 mg BID) with carboplatin (AUC4) 
and paclitaxel $\left(175 \mathrm{mg} / \mathrm{m}^{2}\right)$ followed by olaparib maintenance therapy, compared to standard carboplatin (AUC6) and paclitaxel (175 mg/ $\left.\mathrm{m}^{2}\right)$ in patients with platinum-sensitive, recurrent, high-grade serous EOC. The PFS was 12.2 months (95\% CI, 9.7-15.0) versus 9.6 months (95\% CI, 9.1-9.7) in favour of the olaparib arm (HR 0.51; $\mathrm{p}=0.0012)$. In patients with BRCA mutations, this difference was even greater (HR $0.21 ; \mathrm{p}=0.0015)$. They concluded that the combination cohort had an acceptable and manageable tolerability profile but required upfront dose reduction of chemotherapy. However, the question arises whether this PFS benefit is a result of the simultaneous olaparib, carboplatin, paclitaxel combination or rather a result of olaparib maintenance therapy [27,28]. Dent [47] investigated the tolerability and toxicity of olaparib in combination with weekly paclitaxel $\left(90 \mathrm{mg} / \mathrm{m}^{2}\right)$ in 19 patients with metastatic triple negative breast cancer. Preliminary data did not reach a MTD.

Veliparib in combination with chemotherapy: Veliparib is also investigated in combination with chemotherapy. For EOC, BellMcGuinn [48] compared three arms of veliparib plus chemotherapy and bevacizumab in a phase I trial in patients with previously untreated EOC. The first arm received veliparib plus carboplatin (AUC6), paclitaxel $\left(175 \mathrm{mg} / \mathrm{m}^{2}\right)$ and bevacizumab $(15 \mathrm{mg} / \mathrm{kg})$, the second arm received veliparib plus carboplatin, a lower dose of paclitaxel $\left(80 \mathrm{mg} / \mathrm{m}^{2}\right)$ and bevacizumab and the third arm received veliparib plus cisplatin (75 $\left.\mathrm{mg} / \mathrm{m}^{2}\right)$, paclitaxel $\left(60 \mathrm{mg} / \mathrm{m}^{2}\right)$ and bevacizumab. Preliminary results showed a RP2D of veliparib of $150 \mathrm{mg}$ BID for all schedules. Veliparib has also been investigated in combination with cyclophosphamide in patients with BRCAm or high-grade serous EOC [49]. However, this combination did not result in an improved ORR (PR: $11.8 \% v s$ 19.4\%; CR: $2.9 \%$ vs $2.7 \%$ ) or PFS ( 2.3 vs 2.1 months; $\mathrm{p}=0.68$ ) when compared to cyclophosphamide alone. Gray [50] investigated the effect of veliparib plus carboplatin and gemcitabine in advanced solid tumors in a phase I study. Results showed a RP2D of $250 \mathrm{mg}$ veliparib with carboplatin (AUC 4) and gemcitabine $\left(800 \mathrm{mg} / \mathrm{m}^{2}\right)$ and responses were seen in $69 \%$ of the patients with BRCAm EOC. The efficacy of veliparib with carboplatin and paclitaxel is currently further investigated. NCT02470585 is a phase III trial by the Gynaecologic Oncology Group (GOG), which is currently investigating veliparib with carboplatin and paclitaxel followed by maintenance therapy in patients with primary EOC [51] (Tables 1 and 2).

For breast cancer, Loibl [52] investigated the combination of veliparib (50 mg), carboplatin (AUC6) and paclitaxel $\left(80 \mathrm{mg} / \mathrm{m}^{2}\right)$ for stage II-III triple negative early breast cancer as neoadjuvant therapy in the BrighTNess trial. Three arms were compared: veliparib, carboplatin and paclitaxel versus carboplatin and paclitaxel versus paclitaxel. BRCA 1 or BRCA 2 mutations were found in $14 \%$ of the veliparib, carboplatin and paclitaxel group, $16 \%$ in the carboplatin and paclitaxel group and in $15 \%$ of the paclitaxel group. Results showed a significantly higher pathological complete response for veliparib, carboplatin and paclitaxel group in comparison with paclitaxel alone (53\% vs $31 \%$ $\mathrm{p}<0.0001$ ), but a similar pathological complete response in comparison with the carboplatin plus paclitaxel group ( $53 \%$ vs $58 \% \mathrm{p}=0.36$ ). A phase I trial by Rodler [53] investigated the combination of veliparib (300 mg BID) with cisplatin $\left(75 \mathrm{mg} / \mathrm{m}^{2}\right)$ and vinorelbine $(25 \mathrm{mg} /$ $\left.\mathrm{m}^{2}\right)$ in patients with advanced triple negative and/or BRCAm breast cancer. The combination showed an ORR of 35\% (95\% CI 23-50\%) with a tolerable safety profile. Currently investigations on the efficacy of veliparib plus temozolomide [54] and of veliparib plus carboplatin in patients with breast cancer $[55,56]$ are ongoing. Preliminary results of these trials are depicted in Table 1.
Niraparib in combination with chemotherapy: A study investigating niraparib in combination with carboplatin, carboplatin and paclitaxel or carboplatin and pegylated liposomal doxorubicin (NCT01110603 [57]) and another study with niraparib in combination with pegylated liposomal doxorubicin (PLD) (NCT01227941 [58]) in solid tumours and EOC have been stopped prematurely without explanation.

Rucaparib in combination with chemotherapy: Plummer [59] first investigated pharmacodynamics and pharmacokinetics of rucaparib in combination with temozolomide in patients with advanced solid tumours. Results showed a PARP inhibitory dose of $12 \mathrm{mg} / \mathrm{m}^{2}$. Currently phase II/III trials with PARP inhibitors in combination with chemotherapy are ongoing and results are awaited (Table 2).

\section{Immunotherapy}

There are multiple immune checkpoint inhibitors; pembrolizumab and nivolumab target the programmed death protein-1 (PD-1), avelumab, atezolizumab and durvalumab target the programmeddeath ligand-1 (PD-L1) and ipilimumab and tremelimumab target cytotoxic T-lymphocyte-associated protein 4 (CTLA-4). These immune checkpoint inhibitors have shown to be beneficial in treating several malignancies and are currently studied in female cancers. The combination of PARP inhibition and immune checkpoint inhibition seem especially promising in patients with EOC and HDR deficiency [60]. In fact, tumors with a BRCAm typically harbour TP53 mutations and have a higher mutational load $[61,62]$. Hence, they also harbour a greater number of neoantigens that enhance the recruitment of tumor infiltrating lymphocytes (TILs); in BRCAm tumors a significantly increased expression of CD3+ and CD8+ TILs have been shown [63], as well as increased expression of PD-1 and PD-L1 compared to wild type EOC $[63,64]$. Furthermore, PARP inhibition can modulate immune signalling pathways through various mechanisms $[65,66]$, both activating and non-activating. In vitro a CTLA-4 antibody, but not PD-1/PD-L1 blockade, synergized therapeutically with veliparib [67]. On the other hand, the PARP inhibitor talazoparib increased the number of peritoneal CD8+ T-cells and natural killer cells and increased production of interferon (IFN) ${ }_{-}$and tumor necrosis factor- $\alpha$ in a BRCA1-mutated ovarian cancer xenograft model [68]. The exact immune-modulating effects of checkpoint inhibitor plus PARP inhibitor combinations are currently unknown and needs further research. Currently, multiple trials are therefore investigating these combinations [69-73] (Table 3).

Moreover, it is still uncertain in which clinical setting the use of immune checkpoint inhibitors in EOC is most favourable. PARP inhibitors in combination with immune checkpoint inhibitors might be most beneficial in primary disease or early recurrence due to a lower tumor burden. Future trials will test these combinations in first-line treatment of breast and EOC.

\section{Anti-angiogenic therapy}

Preclinical and clinical evidence suggests that interactions exist between the VEGF pathway and PARP inhibition. Several groups have reported that PARP inhibition reduces VEGF-induced angiogenesis. A preclinical study from Bindra [74] showed that hypoxia is associated with impaired HDR and therefore a state of BRCAness. They also hypothesized that in a hypoxic state the cells are pushed toward NHEJ because of impaired HDR and thus show increased genetic instability and cell death. Liu [75] designed a phase I trial with olaparib BID and cediranib, a tyrosine kinase inhibitor directed against VEGF. The RP2D was cediranib $30 \mathrm{mg}$ daily with olaparib $200 \mathrm{mg}$ BID. Subsequently, Liu 
Citation: Luijten D, Vreeswijk MPG, Boere I, Kroep JR (2018) Current and Future Developments of PARP Inhibitors in the Treatment of Breast and Ovarian Cancer. J Cancer Sci Ther 10: 178-189. doi: 10.4172/1948-5956.1000542

\begin{tabular}{|c|c|c|c|c|c|c|c|c|}
\hline Investigators & Phase & \begin{tabular}{|c|}
$\begin{array}{c}\text { Cancer } \\
\text { type }\end{array}$ \\
\end{tabular} & $\begin{array}{c}\text { No of patients } \\
\text { (BRCAm) }\end{array}$ & Investigational arm & Control arm & $\begin{array}{l}\text { Primary } \\
\text { endpoint }\end{array}$ & Overall result & Previous treatment \\
\hline \multicolumn{9}{|c|}{ Olaparib } \\
\hline Fong et al. [22] & 1 & ST & $60(22)$ & Olaparib (100-600 BID) & -- & $\begin{array}{l}\text { PK, PD, } \\
\text { safety and } \\
\text { tolerability }\end{array}$ & $\begin{array}{l}M A D=600 \mathrm{mg} \mathrm{BID} \\
M T D=400 \mathrm{mg} \text { BID }\end{array}$ & $\begin{array}{c}53 \% \geq 4 \text { prior } \\
\text { treatment regimens }\end{array}$ \\
\hline Tutt et al. [23] & 2 & $\mathrm{BC}$ & $54(54)$ & Olaparib (400 mg BID) & Olaparib 100 mg BID & ORR & $\begin{array}{c}\text { ORR: } 41 \%(400 \text { BID }) v s \\
22 \%(100 \text { BID })\end{array}$ & $\begin{array}{l}\text { Median of } 3 \\
\text { regimens }\end{array}$ \\
\hline Audeh et al. [24] & 2 & EOC & $58(58)$ & Olaparib (400 mg BID) & Olaparib 100 mg BID & ORR & $\begin{array}{c}\text { ORR: } 33 \%(400 \mathrm{BID}) v s \\
13 \%(100 \mathrm{BID})\end{array}$ & $\begin{array}{l}\text { Median of } 3 \\
\text { regimens }\end{array}$ \\
\hline Kaufman et al. [25] & 2 & ST & $298(298)$ & Olaparib (400 mg BID) & -- & TRR & $\begin{array}{c}\text { TRR in BC: } 12.9 \% \\
\text { TRR in OC: } 31.1 \% \\
\text { Overall TRR: } 26.2 \%\end{array}$ & $\begin{array}{l}\text { Median of } 4 \\
\text { regimens }\end{array}$ \\
\hline $\begin{array}{l}\text { Ledermann et al. } \\
\qquad[27,28]\end{array}$ & 2 & EOC & $265(136)$ & Olaparib (400 mg BID) & Placebo 400 mg BID & PFS & $\begin{array}{c}\text { PFS in BRCAm } 11.2 \text { vs } \\
4.3 \text { months } \\
\text { OS no difference }\end{array}$ & $\begin{array}{l}\text { Median of } 3 \\
\text { regimens }\end{array}$ \\
\hline $\begin{array}{l}\text { Robson et al. } \\
\text { (Olympiad) [33] }\end{array}$ & 3 & $\mathrm{BC}$ & $302(302)$ & Olaparib (300 mg BID) & $\begin{array}{l}\text { Prespecified } \\
\text { chemotherapy } \\
\text { regimens }\end{array}$ & PFS & \begin{tabular}{|} 
Median PFS: 7.0 vs 4.2 \\
months \\
HR for disease \\
progression or death: 0.58 \\
$(p<0.001)$ \\
\end{tabular} & $\leq 2$ regimens \\
\hline Balmaña et al. [45] & 1 & $\begin{array}{l}\mathrm{BC} \\
\mathrm{EOC} \\
\mathrm{PC}\end{array}$ & $54(29)$ & $\begin{array}{l}\text { Olaparib }(50-200 \mathrm{mg} \\
\text { BID) continuous vs } \\
\text { intermittent + CDDP } \\
\left(60-75 \mathrm{mg} / \mathrm{m}^{2} \mathrm{IV}\right)\end{array}$ & & $\begin{array}{l}\text { safety and } \\
\text { tolerability }\end{array}$ & $\begin{array}{c}\text { Intermittent olaparib }(50 \\
\text { BID) + cisplatin }\left(60 \mathrm{mg} / \mathrm{m}^{2}\right) \\
\text { ORR: } 41 \%\end{array}$ & $\begin{array}{l}\text { Median of } 3 \\
\text { regimens }\end{array}$ \\
\hline Oza et al. [46] & 2 & EOC & $\begin{array}{c}162 \text { (41 out of } \\
107)\end{array}$ & $\begin{array}{c}\text { Olaparib }(200 \mathrm{BID})+ \\
\text { PTX }\left(175 \mathrm{mg} / \mathrm{m}^{2}\right)+ \\
\text { CBDCA }(\mathrm{AUC} 4 \mathrm{mg} / \mathrm{ml} \\
\text { per min) }\end{array}$ & $\begin{array}{c}\text { PTC }(175 \mathrm{mg} / \\
\left.\mathrm{m}^{2}\right)+\mathrm{CBDCA}(\mathrm{AUC} 4 \\
\mathrm{mg} / \mathrm{ml} \text { per } \mathrm{min})\end{array}$ & PFS & $\begin{array}{l}\text { PFS } 12.3 \text { months vs } 9.6 \\
\text { months }\end{array}$ & $72 \% 1$ regimen \\
\hline Dent et al. [47] & 1 & TNBC & 19 & $\begin{array}{c}\text { Olaparib }(200 \mathrm{mg} \\
\text { BID)+PTX (90 mg/m² } \\
\text { weekly) }\end{array}$ & -- & $\begin{array}{l}\text { Safety and } \\
\text { tolerability }\end{array}$ & $\begin{array}{l}37 \% \mathrm{PR} \\
5 \% \mathrm{SD}\end{array}$ & $\leq 1$ regimen \\
\hline Gelmon et al. [91] & 2 & $\begin{array}{l}\text { EOC } \\
\text { BC }\end{array}$ & $90(27)$ & Olaparib (400 mg BID) & -- & ORR & $\begin{array}{c}\text { ORR in BRCAm OC: } 41 \% \\
\text { ORR in BRCA+ OC: } 24 \% \\
\text { ORR in BC: } 0 \%\end{array}$ & $\begin{array}{l}\text { Median of } 3 \\
\text { regimens }\end{array}$ \\
\hline \multicolumn{9}{|c|}{ Veliparib } \\
\hline Puhalla et al. [34] & 1 & $\begin{array}{c}\mathrm{EOC} \\
\mathrm{BC}\end{array}$ & $80(60)$ & $\begin{array}{l}\text { Veliparib (50-500 mg } \\
\text { BID) }\end{array}$ & -- & $\begin{array}{l}\text { PK, PD, } \\
\text { safety and } \\
\text { tolerability }\end{array}$ & $\mathrm{RP} 2 \mathrm{D}=400 \mathrm{mg} \mathrm{BID}$ & Unknown \\
\hline Coleman et al. [35] & 2 & EOC & $50(50)$ & Veliparib (400 mg BID) & -- & ORR & ORR: $26 \%$ & \begin{tabular}{|c|}
$28 \% 1$ prior \\
regimen, $36 \% 2$ \\
prior regimens, $36 \%$ \\
3 prior regimens \\
\end{tabular} \\
\hline $\begin{array}{l}\text { Bell-McGuinn et al. } \\
\text { [48] }\end{array}$ & 1 & EOC & 189 & $\begin{array}{c}\text { Veliparib (150-200 mg) } \\
+ \text { CBDC(AUC 6)+PTX } \\
\text { (ranging doses) } \\
\text { +bevacizumab (15 } \\
\mathrm{mg} / \mathrm{kg})\end{array}$ & $\begin{array}{c}\text { Veliparib (150-200 } \\
\mathrm{mg})+ \text { CDDP }(75 \mathrm{mg} / \\
\left.\mathrm{m}^{2}\right)+\mathrm{PTX} \text { (ranging } \\
\text { doses) +bevacizumab } \\
(15 \mathrm{mg} / \mathrm{kg}\end{array}$ & $\begin{array}{l}\text { PK, PD, } \\
\text { safety and } \\
\text { tolerability }\end{array}$ & $\begin{array}{c}\mathrm{RP} 2 \mathrm{D}= \\
\text { regiments }\end{array}$ & Unknown \\
\hline Kummar et al. [49] & 2 & EOC & $72(31)$ & $\begin{array}{c}\text { CYC } 50 \text { (mg OD) + } \\
\text { Veliparib(60 mg OD) }\end{array}$ & CYC (50 mg OD) & PFS, ORR & $\begin{array}{l}\text { No difference in PFS or } \\
\text { ORR }\end{array}$ & $\begin{array}{l}\text { Median of } 4 \\
\text { regimens }\end{array}$ \\
\hline $\begin{array}{l}\text { Loibl et al. [52] } \\
\text { (BrighTNess) }\end{array}$ & 2 & $\mathrm{BC}$ & $116(15)$ & $\begin{array}{c}\text { Veliparib }(50 \mathrm{mg})+ \\
\text { CBDCA }(\text { AUC 6) }+ \\
\text { PTX }\left(80 \mathrm{mg} / \mathrm{m}^{2}\right)\end{array}$ & $\begin{array}{c}\text { CBDCA (AUC 6) + } \\
\text { PTX }\left(80 \mathrm{mg} / \mathrm{m}^{2}\right) \\
\text { versus } \\
\text { PTX }\left(80 \mathrm{mg} / \mathrm{m}^{2}\right) \\
\end{array}$ & $\begin{array}{c}\text { Pathological } \\
\text { CR }\end{array}$ & $\begin{array}{c}\text { Pathological CR } 53 \% \\
(\mathrm{~V}+\mathrm{CBDCA}+\mathrm{PTX}) \mathrm{vs} \\
58 \%(\text { CBDCA+PTX }) \text { vs } \\
31 \%(\mathrm{PTX})\end{array}$ & Unknown \\
\hline Gray et al. [50] & 1 & $\begin{array}{c}\mathrm{EOC}+ \\
\mathrm{BC}\end{array}$ & $66(36)$ & $\begin{array}{c}\text { Veliparib + CBCDA } \\
\text { (AUC } 4 \text { )+ gemcitabine } \\
\left(800 \mathrm{mg} / \mathrm{m}^{2}\right)\end{array}$ & - & RP2D & $\begin{array}{c}\text { RP2D: veliparib } 250 \mathrm{mg} \\
+ \text { CBCDA (AUC } 4)^{+} \\
\text {gemcitabine }\left(800 \mathrm{mg} / \mathrm{m}^{2}\right) \\
\text { Responses } 69 \% \text { in } \\
\text { BRCAm EOC }\end{array}$ & $\begin{array}{l}\leq 2 \text { prior } \\
\text { chemotherapu } \\
\text { regimens }\end{array}$ \\
\hline Rodler et al. [53] & 1 & $\mathrm{BC}$ & $45(11)$ & \begin{tabular}{|c|} 
Veliparib dose- \\
escalating + cisplatin \\
$\left(75 \mathrm{mg} / \mathrm{m}^{2}\right)+$ \\
vinorelbine $\left(25 \mathrm{mg} / \mathrm{m}^{2)}\right.$ \\
\end{tabular} & -- & $\begin{array}{l}\text { PK, PD, } \\
\text { Safety and } \\
\text { toxicity }\end{array}$ & $\begin{array}{l}\text { Veliparib } 300 \mathrm{mg} \mathrm{BID} \text { is } \\
\text { well tolerated }\end{array}$ & Unknown \\
\hline Isakoff et al. [54] & 2 & $\mathrm{BC}$ & 41 & $\begin{array}{c}\text { Veliparib (40 mg BID } \\
\text { days } 1-7) \text { and TMZ } \\
\left(150 \mathrm{mg} / \mathrm{m}^{2} \text { days } 1-5\right)\end{array}$ & -- & efficacy & $\begin{array}{c}\text { 1CR, } 2 \mathrm{PR}, 7 \mathrm{SD} \text { (all } \\
\text { unconfirmed), and } 14 \mathrm{PrD}\end{array}$ & Unknown \\
\hline Somlo et al. [55] & 2 & $\mathrm{BC}$ & $26(26)$ & Veliparib & $\begin{array}{l}\text { Veliparib + } \\
\text { carboplatin }\end{array}$ & ORR & 3 CR (12\%), 9 PR (35\%) & $\begin{array}{c}1 \text { prior } \\
\text { chemotherapy } \\
\text { regimen }\end{array}$ \\
\hline Wesolowski et al. [56] & 1 & $\mathrm{BC}$ & $44(16)$ & $\begin{array}{c}\text { Veliparib +CBDCA in } \\
\text { different regimens }\end{array}$ & -- & $\begin{array}{l}\text { Safety and } \\
\text { toxicity }\end{array}$ & $18.6 \%$ PR; $48.8 \%$ SD & Unknown \\
\hline
\end{tabular}


Citation: Luijten D, Vreeswijk MPG, Boere I, Kroep JR (2018) Current and Future Developments of PARP Inhibitors in the Treatment of Breast and Ovarian Cancer. J Cancer Sci Ther 10: 178-189. doi: 10.4172/1948-5956.1000542

\begin{tabular}{|c|c|c|c|c|c|c|c|c|}
\hline \multicolumn{9}{|c|}{ Niraparib } \\
\hline Sandhu et al. [36] & 1 & ST & $100(29)$ & $\begin{array}{c}\text { Niraparib (30-400 mg } \\
\text { OD) }\end{array}$ & -- & $\begin{array}{l}\text { PK, PD, } \\
\text { safety and } \\
\text { tolerability }\end{array}$ & RP2D 300 mg/day & $\begin{array}{l}\text { Median of } 5 \\
\text { regimens }\end{array}$ \\
\hline Mirza et al. [37] & 3 & EOC & $553(203)$ & Niraparib (300 mg OD) & Placebo (300 mg OD) & PFS & $\begin{array}{c}\text { PFS } 21.0 \text { vs. } 5.5 \text { months } \\
\text { in BRCAm group } \\
\text { PFS } 12.0 \text { vs } 3.9 \text { months in } \\
\text { BRCA }+ \text { group }\end{array}$ & \begin{tabular}{|c|} 
Olaparib group: \\
$0.7 \% 1$ regimen, \\
$50,7 \% 2$ regimens, \\
$48.6 \% 3$ regimens \\
Placebo group: $0 \%$ \\
1 regimen, $46.2 \% 2$ \\
regimens, $53.8 \% 3$ \\
regimens
\end{tabular} \\
\hline \multicolumn{9}{|c|}{ Rucaparib } \\
\hline Kristeleit et al. [41] & 1 & ST & 56 & \begin{tabular}{|c|} 
Rucaparib 40 QD-840 \\
mg BID
\end{tabular} & -- & MTD, RP2D & RP2D of $600 \mathrm{mg} \mathrm{BID}$ & Unclear \\
\hline Drew et al. [42] & 2 & $\begin{array}{c}\text { EOC, } \\
\text { BC }\end{array}$ & $78(78)$ & $\begin{array}{c}\text { Rucaparib (4-18 mg/ } \\
\left.\mathrm{m}^{2}\right)\end{array}$ & $\begin{array}{l}\text { Rucaparib (92 mg } \\
\text { OD-600 mg BID) }\end{array}$ & ORR & $\begin{array}{c}\text { ORR of } 2 \% \\
41 \% \text { SD of } \geq 12 \text { weeks }\end{array}$ & -- \\
\hline $\begin{array}{l}\text { Swisher et al. (ARIEL } \\
\text { 2) [43] }\end{array}$ & 2 & EOC & $204(40)$ & $\begin{array}{l}\text { Rucaparib (600 mg } \\
\text { BID) }\end{array}$ & -- & PFS & $\begin{array}{c}\text { PFS HR: } 0.27, p<0.001 \\
\text { BRCAm and LOH high vs } \\
\text { LOH low }\end{array}$ & $\begin{array}{l}\text { 3-4 prior } \\
\text { chemotherapy } \\
\text { regiments }\end{array}$ \\
\hline $\begin{array}{l}\text { Coleman et al. } \\
\text { (ARIEL3) [44] }\end{array}$ & 3 & EOC & $564(196)$ & $\begin{array}{c}\text { Rucaparib (600 mg } \\
\text { BID) }\end{array}$ & Placebo & PFS & $\begin{array}{c}\text { PFS BRCAm HR: } 0.23 ; \\
p<0.0001\end{array}$ & $\geq 2$ regimens \\
\hline Plummer et al. [59] & 1 & ST & 33 & $\begin{array}{c}\text { Rucaparib }(1-18 \mathrm{mg} / \\
\left.\mathrm{m}^{2}\right)+\mathrm{TMZ}\left(100 \mathrm{mg} / \mathrm{m}^{2}\right)\end{array}$ & -- & $\begin{array}{l}\text { PK, PD, } \\
\text { safety and } \\
\text { tolerability }\end{array}$ & PID of $12 \mathrm{mg} / \mathrm{m}^{2}$ & Unclear \\
\hline \multicolumn{9}{|c|}{ Talazoparib } \\
\hline De Bono et al. [92] & 1 & \begin{tabular}{|} 
EOC, \\
BC, PC, \\
CC, \\
PrC, ST
\end{tabular} & $39(24)$ & $\begin{array}{c}\text { Talazoparib (25-1100 } \\
\mu \mathrm{g} \text { OD) }\end{array}$ & -- & $\begin{array}{l}\text { PK, PD, } \\
\text { safety and } \\
\text { tolerability }\end{array}$ & MTD $1000 \mu \mathrm{g} / \mathrm{d}$ & -- \\
\hline \multicolumn{9}{|c|}{$\begin{array}{l}\text { BC Breast Cancer, BID Bi-Daily, CBDCA Carboplatin, CDDP Cisplatin CR Complete Response, CYC Cyclophosphamide, EOC Epithelial Ovarian Cancer Including Primary } \\
\text { Peritoneal and Fallopian Tube Cancer, MAD maximum Administered Dose, MTD Maximum Tolerated Dose, OD Omni Die, ORR Overall Response Rate, OS Overall } \\
\text { Survival, PC Pancreatic Cancer, PD Pharmacodynamics, PrD Progressive Disease, PFS Progression Free Survival, PID PARP Inhibitory Dose, PK Pharmacokinetics, } \\
\text { PR Partial Response, PrC Prostate Cancer, PTX Paclitaxel, RP2D Recommended Phase II Dose, SD Stabile Disease, ST Solid Tumors, TMZ Temozolomide, TRR } \\
\text { Tumor Response rate }\end{array}$} \\
\hline
\end{tabular}

Table 1: Summarizing finished trials.

[76] investigated the efficacy of olaparib in combination with cediranib in a phase II trial in 90 patients with recurrent platinum-sensitive EOC. Results showed a PFS of 17.7 months for treatment with olaparib and cediranib versus 9.0 months for olaparib monotherapy. A post-hoc analysis showed that median PFS was even greater for patients with a g BRCA1/2m: 19.4 months in the combination arm compared to 16.5 months in the olaparib monotherapy group respectively. Most common grade 3 toxicities in the olaparib plus cediranib group were fatigue, diarrhoea and hypertension. Dose reductions were necessary in $77 \%$ and $24 \%$ of patients respectively. Zimmer [77] performed a phase I study investigating the RP2D for durvalumab+olaparib+cediranib in recurrent female cancers. They concluded a RP2D of $1500 \mathrm{mg}$ q28d durvalumab $+300 \mathrm{mg}$ BID olaparib $+20 \mathrm{mg} 5$ days on $/ 2$ days off cediranib is tolerable and active.

Overall, anti-angiogenetic therapy in combination with PARP inhibition seems promising due its efficacy and potential synergism. Currently many trials are investigating the combination of bevacizumab or cediranib with PARP inhibitors in ovarian or breast cancer, some of which are listed in Table 3.

Resistance to PARP inhibitors: Clinical trials have shown promising results. However, many studies have described disease progression. Also, thus far PARP inhibitors have failed to show OS benefit. The lack of OS proven benefit can be partly explained by treatment effects of post-progression therapy. Another explanation is resistance to PARP inhibitors. Lord and Ashworth describe four pathways that lead to resistance against PARP inhibitors [78]. Most of the studies that have been done in vitro, with mice with different kind of knock-out genes. The first mechanism is the occurrence of a secondary mutation in the affected BRCA gene that would lead to the restoration of the BRCA open reading frame. Due to this restoration, the BRCA gene can be translated and lead to (partial) functional protein to repair DSBs. Several studies have reported this phenomenon in patients who had developed resistance to PARP inhibitors [78]. The second mechanism depends on the (partial) restoration of HDR due to the somatic loss of expression of genes involved in the regulation of DSB repair pathway choice, such as the tumor suppressor p53-binding protein 1 (53BP1) [78] or REV7 [79]. This mechanism is shown in vivo in mice $[78,79]$. A very recent publication describes the identification of shieldin, a complex of REV7, RINN1, RINN2 and RINN3 proteins. This complex restrains DNA end resection and thereby promotes NHEJ. Deletion of one of the shield in components leads to resistance to PARP inhibitors in BRCA-1 depleted cells [80]. Thirdly, the upregulation of the P-glycoprotein efflux pump, which pumps PARP inhibitors out of the cell resulting in a decreased inhibition of PARP [78]. The fourth mechanism is the hypothesis that poses that acquired PARP1 loss-offunction mutations or down-regulation of transcription can result in PARP inhibitor resistance [78].

Another mechanism explaining resistance is replication fork stabilization. Deficiencies in PAX-interacting protein 1(PTIP), Chromodomain-helicase-DNA-binding protein 4 (CHD4) and PARP1 limit the action of MRE11 to single-strand DNA at stalled replication forks. MRE11 is involved in the degradation of stalled replication forks. When MRE11 dependent replication fork degradation is absent due to deficiencies in PTIP, CHD4 or PARP1, nascent DNA strands will be protected from degradation and therefore the cell will be resistant to PARP inhibition [81]. BRCA-deficient cells become resistant to 
Citation: Luijten D, Vreeswijk MPG, Boere I, Kroep JR (2018) Current and Future Developments of PARP Inhibitors in the Treatment of Breast and Ovarian Cancer. J Cancer Sci Ther 10: 178-189. doi: 10.4172/1948-5956.1000542

\begin{tabular}{|c|c|c|c|c|c|c|}
\hline Trial $\mathrm{Nr}$ & Phase & Cancer type & Investigational arm & Second arm & Third arm & Primary endpoint \\
\hline \multicolumn{7}{|c|}{ Olaparib } \\
\hline NCT02032823 (OlympiA) [31] & 3 & $\mathrm{BC}$ & Olaparib (300 mg BID) & Placebo & -- & IDFS \\
\hline NCT01844986 (SOLO-1) [30] & 3 & EOC & Olaparib (300 mg BID) & Placebo & -- & PFS \\
\hline NCT01874353 [93] & 3 & EOC (after CR or PR) & Olaparib (300 mg BID) & Placebo & -- & PFS \\
\hline NCT01081951 [94] & 2 & EOC & $\begin{array}{c}\text { Olaparib }(200-400 \mathrm{mg} \text { BID) + PTX } \\
\left(175 \mathrm{mg} / \mathrm{m}^{2}\right)+\text { CBDCA (AUC 4) }\end{array}$ & $\begin{array}{l}\text { PTX }\left(175 \mathrm{mg} / \mathrm{m}^{2}\right)+ \\
\text { CBDCA (AUC 4) }\end{array}$ & -- & PFS \\
\hline NCT01445418 [95] & 1 & $\mathrm{EOC} / \mathrm{BC}$ & Olaparib +CBDCA dose escalation & -- & -- & Safety and toxicity \\
\hline NCT02418624 (REVIVAL) [96] & 1 & $\begin{array}{l}\text { BC/EOC/advanced } \\
\text { cancer }\end{array}$ & Olaparib + CBDCA dose escalation & -- & -- & MTD \\
\hline NCT02561832 [97] & 1 & $\mathrm{BC}$ & $\begin{array}{l}\text { Olaparib + CBDCA + amtharacycline } \\
+ \text { cyclophosphamide dose escalation }\end{array}$ & -- & - & AE. pCR \\
\hline NCT00707707 [98] & 01-Feb & $\mathrm{BC} / \mathrm{TNBC}$ & Olaparib + PTX & -- & -- & $\mathrm{AE}$ \\
\hline NCT00782574 [99] & 1 & ST & Olaparib + CDDP & & & Safety and toxicity \\
\hline NCT00516724 [100] & 1 & $\mathrm{BC} / \mathrm{EOC}$ & Olaparib+ CBDCA & Olaparib+ PTX & $\begin{array}{c}\text { Olaparib + } \\
\text { CBDCA +PTX }\end{array}$ & MTD \\
\hline \multicolumn{7}{|c|}{ Veliparib } \\
\hline NCT01472783 (Veli-BRCA) [101] & 01-Feb & EOC & Veliparib (300 mg BID) & -- & -- & MTD, RP2D, ORR \\
\hline NCT01690598 [102] & 01-Feb & EOC & Veliparib (30 mg BID)+ Topotecan & -- & -- & MTD, ORR \\
\hline NCT01506609 [103] & - & $\mathrm{BC}$ & $\begin{array}{c}\left(2 \mathrm{mg} / \mathrm{m}^{2}\right) \\
\text { Veliparb }(40 \mathrm{mg} \mathrm{BID})+\text { temozolomide } \\
\left(150-200 \mathrm{mg} / \mathrm{m}^{2}\right)\end{array}$ & $\begin{array}{c}\text { Veliparib }(120 \mathrm{mg} \\
\text { BID)+CBDCA (AUC } \\
6)+\operatorname{PTX~}\left(175 \mathrm{mg} / \mathrm{m}^{2}\right)\end{array}$ & $\begin{array}{l}\text { placebo }(120 \mathrm{mg} \\
\text { BID)+ CBDCA } \\
(\text { AUC } 6)+\text { PTX } \\
\left(175 \mathrm{mg} / \mathrm{m}^{2}\right)\end{array}$ & PFS \\
\hline NCT02163694 [104] & 3 & $\mathrm{BC}$ & Veliparib+ CBDCA +PTX & $\begin{array}{c}\text { Placebo + CBDCA } \\
+ \text { PTX }\end{array}$ & & PFS \\
\hline NCT02032277 [105] & 3 & TNBC & Veliparib+CBDCA + PTX + AC & $\begin{array}{c}\text { Placebo+ CBDCA + } \\
\text { PTX + AC }\end{array}$ & $\begin{array}{l}\text { Placebo + PTX } \\
+ \text { AC }\end{array}$ & $\mathrm{pCR}$ \\
\hline NCT01149083 [106] & 2 & $\mathrm{BC}$ & Veliparib & Veliparib + CBDCA & & $\mathrm{RR}$ \\
\hline NCT02470585 [51] & 3 & EOC & $\begin{array}{l}\text { Veliparib }+\mathrm{PTX}+\mathrm{CBDCA} \text { with } \\
\quad \text { veliparib maintenance }\end{array}$ & $\begin{array}{c}\text { Veliparib + PTX } \\
\text { +CBDCA with } \\
\text { placebo maintenance }\end{array}$ & $\begin{array}{c}\text { placebo + } \\
\text { PTX +CBDCA } \\
\text { with placebo } \\
\text { maintenance } \\
\end{array}$ & PFS \\
\hline \multicolumn{7}{|c|}{ Niraparib } \\
\hline NCT01905592 (BRAVO) [39] & 3 & $\mathrm{BC}$ & Niraparib (3 x $100 \mathrm{mg}$ OD) & Physician's choice & -- & PFS \\
\hline NCT02826512 [107] & 2 & $\mathrm{BC}$ & Niraparib (300 mg OD) & -- & -- & PFS \\
\hline NCT02354586 (QUADRA) [108] & 2 & EOC & Niraparib & -- & -- & $\begin{array}{l}\text { Anti-tumour } \\
\text { activity }\end{array}$ \\
\hline NCT02655016 (PRIMA) [40] & 3 & EOC & Niraparib & Placebo & -- & PFS \\
\hline \multicolumn{7}{|c|}{ Rucaparib } \\
\hline NCT02855944 (ARIEL4) [109] & 3 & EOC & Rucaparib (600 mg BID) & CT & -- & PFS \\
\hline NCT01482715 [110] & 1 & $\mathrm{EOC} / \mathrm{ST}$ & Rucaparib dose escalating & -- & -- & $\begin{array}{c}\text { PK, PD, safety and } \\
\text { tolerability }\end{array}$ \\
\hline NCT01074970 [111] & 2 & TNBC & $\begin{array}{c}\text { Rucaparib (24-30 mg)+CDDP(75 } \\
\left.\mathrm{mg} / \mathrm{m}^{2}\right)\end{array}$ & $\operatorname{CDDP}\left(75 \mathrm{mg} / \mathrm{m}^{2}\right)$ & -- & $2 y$-DFS \\
\hline \multicolumn{7}{|c|}{ Talazoparib } \\
\hline NCT01945775 (EMBRACA) [112] & 3 & $\mathrm{BC}$ & Talazoparib (1 mg OD) & $\begin{array}{l}\text { Physician's choice } \\
\text { CT }\end{array}$ & & PFS \\
\hline NCT02034916 (ABRAZO) [113] & 2 & $\mathrm{BC}$ & Talazoparib (1 mg OD) & -- & -- & ORR \\
\hline NCT02282345 [114] & 2 & $\mathrm{BC}$ & Talazoparib (1 mg OD) & -- & -- & Toxicity \\
\hline NCT02401347 [115] & 2 & $\mathrm{BC}$ & Talazoparib (1 mg OD) & -- & - & ORR \\
\hline NCT02836028 [116] & 2 & EOC & Talazoparib (1 mg OD) & $\begin{array}{c}\text { Talazoparib(1 mg/ } \\
\text { OD) + temozolomide } \\
\left(37.5 \mathrm{mg} / \mathrm{m}^{2}\right)\end{array}$ & -- & ORR \\
\hline $\begin{array}{l}\text { AC doxorubicin/cyclophosphamid } \\
\text { response, EOC Epithelial Ovariar } \\
\text { Dose, OD Omni Die, ORR Overe } \\
\text { Response Rate (RECIST), ST So } \\
\end{array}$ & $A E A$ & $\begin{array}{l}\text { se Events, BC Br } \\
\text { uding Primary Perit }\end{array}$ & $\begin{array}{l}\text { ancer, BID bi-daily, CBDCA C } \\
\text { and Fallopian Tube Cancer, IDF } \\
\text { iomplete Response, PFS Progre } \\
\text { east Cancer, 2y-DFS } 2 \text { Year Dis }\end{array}$ & $\begin{array}{l}\text { platin, CDDP Cis } \\
\text { terval Disease-Fre } \\
\text { n Free Survival, P } \\
\text { Free Survival. }\end{array}$ & $\begin{array}{l}\text { CT Chem } \\
\text { rvival, MAD }\end{array}$ & $\begin{array}{l}\text { apy, CR Complete } \\
\text { mum Administered } \\
\text { tial Response, RR }\end{array}$ \\
\hline
\end{tabular}

Table 2: Summarizing ongoing trials of PARP inhibitor monotherapy or in combination with chemotherapy (last updated: 20-12-2017).

various of DNA-damaging agents through the loss of PTIP, PARP1 and CHD4. Furthermore, Survival analysis of patients with EOC with a BRCA2 mutation treated with platinum chemotherapy showed that high PTIP expression has a correlation with a longer PFS [81].
Furthermore, increased phosphorylation of ribosomal protein S6 leading to upregulation of the mTOR pathway [82] and upregulation of NF-kB signalling [83] can also lead to PARP inhibitor resistance. Based on these mechanisms it was hypothesized that PARP inhibitor resistant 
Citation: Luijten D, Vreeswijk MPG, Boere I, Kroep JR (2018) Current and Future Developments of PARP Inhibitors in the Treatment of Breast and Ovarian Cancer. J Cancer Sci Ther 10: 178-189. doi: 10.4172/1948-5956.1000542

\begin{tabular}{|c|c|c|c|c|c|c|}
\hline Trial $\mathrm{Nr}$ & Phase & Cancer type & Investigational arm & Second arm & Third arm & Primary endpoint \\
\hline \multicolumn{7}{|c|}{ Immunotherapy } \\
\hline NCT02571725 [69] & 01-Feb & EOC & $\begin{array}{c}\text { Olaparib }(300 \mathrm{mg} \mathrm{BID})+ \\
\text { tremelimumab escalation dose }\end{array}$ & -- & -- & RP2D, ORR \\
\hline NCT02734004 (MEDIOLA) [70] & 01-Feb & $\begin{array}{l}\mathrm{EOC} / \mathrm{BC} / \mathrm{GC} / \\
\mathrm{SCLC}\end{array}$ & $\begin{array}{c}\text { Olaparib (300 mg BID) +durvalumab } \\
\text { (1.5 g/4 weeks) }\end{array}$ & -- & -- & DCR \\
\hline NCT02953457 [71] & 01-Feb & EOC & Olaparib +tremlimumab+ durvalumab & -- & -- & DLT, PFS \\
\hline NCT02657889 (TOPACIO) [73] & 01-Feb & $\mathrm{BC} / \mathrm{TNBC} / \mathrm{EOC}$ & $\begin{array}{l}\text { Olaparib (dose escalation up to } 300 \\
\mathrm{mg} / \text { day })+ \text { pembrolizumab }(200 \mathrm{mg})\end{array}$ & -- & -- & RP2D, ORR \\
\hline \multicolumn{7}{|c|}{ Anti-angiogenic therapy } \\
\hline NCT02345265 [117] & 2 & EOC & Olaparib + cediranib maleate & -- & -- & $\begin{array}{l}\text { Biomarker } \\
\text { signature } \\
\text { development, } \\
\text { ORR, PFS }\end{array}$ \\
\hline NCT01116648 [118] & 01-Feb & EOC/TNBC & Olaparib +cediranib maleate & Olaparib & -- & DLT, MTD, PFS \\
\hline NCT02354131 (AVANOVA) [119] & 01-Feb & EOC & Niraparib + bevacizumab & $\begin{array}{c}\text { Niraparib } \\
\text { monotherapy }\end{array}$ & -- & PFS \\
\hline NCT02498613 [120] & 2 & Advanced ST & Olaparib + cediranib maleate & -- & -- & ORR \\
\hline NCT03278717 & \multirow{2}{*}{3} & \multirow{2}{*}{ EOC } & \multirow{2}{*}{$\begin{array}{c}\text { Olaparib (300 mg BID) + cediranib (20 } \\
\text { mg/day })\end{array}$} & \multirow{2}{*}{$\begin{array}{l}\text { Olaparib (300 mg } \\
\text { BID) }\end{array}$} & \multirow{2}{*}{--} & \multirow{2}{*}{ PFS, OS } \\
\hline (ICON9) [121] & & & & & & \\
\hline NCT02446600 [122] & 3 & EOC & Platinum-based chemotherapy & Olaparib & Olaparib + cediranib maleate & PFS \\
\hline NCT02477644 (PAOLA-1) & 3 & EOC & $\begin{array}{c}\text { Olaparib (300 mg BID) + bevacizumab } \\
(15 \mathrm{mg} / \mathrm{kg} \text { every } 3 \text { weeks })\end{array}$ & \begin{tabular}{|c|} 
Placebo + \\
bevacizumab $(15$ \\
$\mathrm{mg} / \mathrm{kg}$ every 3 \\
weeks)
\end{tabular} & -- & -- \\
\hline \multicolumn{7}{|c|}{ Anti-angiogenic therapy and immunotherapy } \\
\hline NCT02484404 [72] & 01-Feb & $\begin{array}{c}\mathrm{ST} / \mathrm{EOC} / \\
\mathrm{TNBC} / \mathrm{LC} / \mathrm{PrC} / \\
\mathrm{CC}\end{array}$ & $\begin{array}{l}\text { Olaparib (200-300 mg BID) + } \\
\text { durvalumab }(3-10 \mathrm{mg} / \mathrm{kg})\end{array}$ & $\begin{array}{c}\text { Cediranib } \\
(15-30 \mathrm{mg})+ \\
\text { durvalumab }(10 \\
\mathrm{mg} / \mathrm{kg})\end{array}$ & $\begin{array}{c}\text { Olaparib }(200-300 \mathrm{mg} \\
\text { BID)+Cediranib }(15-30 \\
\mathrm{mg})+ \text { durvalumab }(10 \mathrm{mg} / \mathrm{kg})\end{array}$ & RP2D, ORR \\
\hline \multicolumn{7}{|c|}{$\begin{array}{l}\text { AE Adverse Events, AC doxorubicin/cyclophosphamide, BC Breast Cancer, BID Bi-Daily, CC Colorectal Cancer, CT Chemotherapy, DCR, Disease Control Rate, } \\
\text { EOC Epithelial Ovarian Cancer Including Primary Peritoneal and Fallopian Tube Cancer, GC Gastric Cancer, IDFS Interval Disease-Free Survival, MAD Maximum } \\
\text { Administered Dose, ORR Overall Response Rate, pCR Pathologic Complete Response, PFS Progression Free Survival, PrC Prostate Cancer, RP2D Recommended } \\
\text { Phase } 2 \text { Dose, RR Response Rate (RECIST), ST Solid Tumours, TNBC Triple Negative Breast Cancer, 2y-DFS 2-Year Disease Free Survival }\end{array}$} \\
\hline
\end{tabular}

Table 3: Summarizing current running trials of PARP inhibitor in combination with immunotherapy or anti-angiogenic treatment.

tumors should be treated with rapamycin (an mTOR inhibitor) or with bortezomib (a proteasome inhibitor). The combination of PARP inhibition and rapamycin effectively suppressed tumor growth in mice [82] and the combination of PARP inhibition plus bortezomib led to increased cell death in PARP inhibitor resistant cells [83]. Further investigations (both preclinical and clinical) of mechanisms of PARP inhibitor resistance will direct us to strategies that will optimally use PARP inhibitors in the clinic.

Biomarkers: Considering the application of PARP inhibitors beyond BRCAm tumors, it is essential to identify those patients that benefit most from PARP inhibitors to maximize treatment effect, prevent futile therapy, toxicity and limit health care costs. Several studies have already shown that there is an additional group of tumors with HDR deficiency that also respond to PARP inhibitors $[37,84]$. These tumours have a so called 'BRCAness' phenotype, a deficiency in HR in the absence of a BRCA mutation, which makes them responsive to PARP inhibitors.

Currently, different approaches have been used to identify HDR deficiency or BRCAness. The first way is to analyse tumours for loss of function mutations in genes that are involved in HDR. These genes include ataxia telangiectasia mutated (ATM), ataxia telangiectasia and Rad3-related (ATR), CHEK2, BRIP1, PALB2, RAD51C and RAD51D [84]. The second way to detect BRCAness is via transcriptional signatures. Larsen [85] analysed 55 familial germline BRCA1 or BRCA2 mutated breast cancer patients and 128 patients with sporadic breast cancer. They designed a transcriptional signature to distinguish BRCA1 tumors from sporadic tumors with an accuracy of $83 \%$ and BRCA2 tumors with $89 \%$, which was validated in independent data sets. This transcriptional signature might also be used to identify BRCAness in non BRCA related tumors. The third way to detect BRCAness is through the detection of a genomic signature in a tumor. These signatures represent a pattern of mutations or genomic alterations which are characteristic for the use of error prone repair pathways in the absence of HDR [86]. These patterns consist of specific nucleotide substitutions (e.g. mutational signature 3) or sequence microhomology at breakpoints [87]. An algorithm based on the integration of six signatures associated with BRCA deficiency (including somatic nucleotide substitutions, insertion/deletion and rearrangement patterns), termed HRDetect was developed by Davies [88] Recently, also SNP based profiling has been used to define a so-called HDR deficiency score, based on the combination of three DNA-based measures of genomic instability (i.e. loss of heterozygosity (LOH), telomeric allelic imbalance (TAI) and large-scale transitions (LST)) [89]. This is the myChoice HDR deficiency test (Myriad Genetic) which was used in the NOVA trial as discussed earlier, but it could not discriminate between patients that showed a benefit from treatment niraparib or not [37]. A more recent approach to detect BRCAness is through functional biomarkers or a functional test for current HDR deficiency [15,90]. After the induction of DNA DSBs in fresh tumor tissue ex-vivo, RAD51 protein will accumulate at the sites of the breaks. This key step in the HDR pathway can be visualized by immunofluorescent staining as foci in the nucleus. The inability to form RAD51 foci after induction of DSBs in replicating tumor cells is a biomarker for BRCAness. However, this biomarker technique requires fresh tumor tissue before start of chemotherapy [91-100]. Finally, in the 
Citation: Luijten D, Vreeswijk MPG, Boere I, Kroep JR (2018) Current and Future Developments of PARP Inhibitors in the Treatment of Breast and Ovarian Cancer. J Cancer Sci Ther 10: 178-189. doi: 10.4172/1948-5956.1000542

ARIEL3 trial [44], the percentage of genome wide LOH quantification was used to compare effectiveness of rucaparib amongst groups with high or low genomic LOH levels. Tumors with high LOH appear to respond better to PARP inhibitor therapy and therefore genomic LOH quantification might be used to identify patients who might benefit from PARP inhibitors [101-122].

Concluding, it is essential to identify those patients that benefit most from PARP inhibitors. However, the most optimal test to identify BRCAness has not been determined yet.

\section{Discussion}

PARP inhibitors show promising results in the treatment of EOC, breast cancer as well as other HR related malignancies, but there are still some obstacles to overcome. All randomized phase II/III trials showed a benefit in PFS, but a statistically significant benefit in OS has not been shown yet. It should be further investigated whether this insignificant difference in OS is caused by confounding by later treatment with PARP inhibitors or subsequent therapy or whether there truly is no benefit in OS with PARP inhibitors. Moreover, results of phase III trials investigating the efficacy of PARP inhibitor as maintenance therapy are still awaiting OS data. Results from these trials may give us greater insight whether or not there is a benefit in OS with PARP inhibitors.

\section{Conclusion}

Recently, it was concluded that PARP inhibition is beneficial in the treatment of EOC regardless of the BRCA status [37]. However, the question might arise whether the biomarker was accurately enough to determine the HDR deficiency status of the tumor and therefore precisely define patients with BRCAness. Clearly, there is a need for a most optimal test identifying true HDR deficiency status. Future research should determine the role of PARP inhibition in the treatment of non- BRCAm EOC in respect to maintenance therapy in primary disease after first-line therapy, alone or in combination with immunotherapy or VEGF targeted therapy or combined with chemotherapy. Furthermore, ongoing trials will reveal further knowledge on the positioning as first-line or later line therapy and its role in combination with standard chemotherapy. Combinations with immunotherapy and anti-angiogenic therapy are also promising and need further clarification. Finally, the role of PARP inhibition after previous PARP inhibitor exposure needs to be elucidated. Improved knowledge on these questions will be key to improve the selection of patients that benefit most of (combination therapy with) PARP inhibition.

\section{References}

1. Kuchenbaecker KB, Hopper JL, Barnes DR, Phillips KA, Mooij TM, et al (2017) Risks of breast, ovarian, and contralateral breast cancer for BRCA1 and BRCA2 mutation carriers. JAMA 317: 2402-2416.

2. Farmer H, McCabe N, Lord CJ, Tutt AN, Johnson DA, et al. (2005) Targeting the DNA repair defect in BRCA mutant cells as a therapeutic strategy. Nature 434: 917-921.

3. Bryant HE, Schultz N, Thomas HD, Parker KM, Flower D, et al. (2005) Specific killing of BRCA2-deficient tumors with inhibitors of poly(ADP-ribose) polymerase. Nature 434: 913-917

4. Hoeijmakers JH (2001) Genome maintenance mechanisms for preventing cancer. Nature 411: 366-374.

5. Minli Wang, Weizhong Wu, Wenqi Wu, Bustanur Rosidi, Lihua Zhang, et al (2006) PARP-1 and Ku compete for repair of DNA double strand breaks by distinct NHEJ pathways. Nucleic Acids Res 34: 6170-6182.

6. Ashworth A (2008) A synthetic lethal therapeutic approach: Poly(ADP) ribose polymerase inhibitors for the treatment of cancers deficient in DNA doublestrand break repair. J Clin Oncol 26: 3785-3790.
7. Roy R, Chun J, Powell SN (2011) BRCA1 and BRCA2: Different roles in a common pathway of genome protection. Nat Rev Cancer 12: 68-78.

8. Lord CJ, Ashworth A (2008) Targeted therapy for cancer using PARP inhibitors Curr Opin Pharmacol 8: 363-369.

9. Wei H, Yu X (2016) Functions of Parylation in DNA damage repair pathways Genomics Proteomics Bioinformatics 14: 131-139.

10. Ratnam K, Low JA (2007) Current development of clinical inhibitors of poly(ADP-Ribose) polymerase. Oncology Clin Cancer Res 13: 1383-1388.

11. Helleday $T$ (2011) The underlying mechanism for the PARP and BRCA synthetic lethality: Clearing up the misunderstandings. Molecular oncology 5 : 387-393.

12. Lord CJ, Ashworth A (2017) PARP inhibitors: Synthetic lethality in the clinic. Science 355: 1152-1158.

13. Murai J, Huang S, Das BB, Renaud A, Zhang Y, et al. (2012) Differential trapping of PARP1 and PARP2 by clinical PARP inhibitors. Cancer Res 72 5588-5599.

14. Livraghi L, Garber JE (2015) PARP inhibitors in the management of breast cancer: Current data and future prospects. BMC Med 13:188.

15. Naipal KA, Verkaik NS, Ameziane N, Van Deurzen $C H$, Ter Brugge $P$, et al (2014) Functional ex vivo assay to select homologous recombination-deficien breast tumours for PARP inhibitor treatment. Clin Cancer Res 20: 4816-4826.

16. European Medicine Agency (2018) An overview of Lynparza and why it is authorised in the EU. Lynparza 2: 1

17. Food \& Drug Administration (2018) Lynparza 2: 1.

18. https://www.accessdata.fda.gov/drugsatfda_docs/label/2016/209115s000lbl. pdf

19. https://www.accessdata.fda.gov/drugsatfda docs/label/2018/209115s003lbl. pdf

20. Food \& Drug Administration (2017) Zejula (niraparib) 2: 1.

21. European Medicines Agency (2017) Zejula: EPAR - public assessment report

22. Fong PC, Boss DS, Yap TA, Tutt A, Wu P, et al. (2009) Inhibition of Poly(ADPRibose) polymerase in tumours from BRCA mutation carriers. $N$ Engl $J$ Med 361: 123-134.

23. Tutt A, Robson M, Garber JE, Domchek SM, Audeh MW, et al. (2010) Oral poly (ADP-ribose) polymerase inhibitor olaparib in patients with BRCA1 or BRCA2 mutations and advanced breast cancer: A proof-of-concept trial. Lancet 376 : 235-244.

24. Audeh MW, Carmichael J, Penson RT, Friedlander M, Powell $B$, et al. (2010) Oral poly(ADPribose) polymerase inhibitor olaparib in patients with BRCA1 or BRCA2 mutationsand recurrent ovarian cancer: A proof-of-concept trial. Lancet 376: 245-251.

25. Kaufman B, Shapira-Frommer R, Schmutzler RK, Audeh MW, Friedlander M et al. (2015) Olaparib monotherapy in patients with advanced cancer and a germline BRCA1/2 mutation. J Clin Oncol 33: 244-250.

26. Ledermann J, Harter P, Gourley C, Friedlander M, Vergote, et al. (2012) Olaparib maintenance therapy in platinum-sensitive relapsed ovarian cancer. N Engl J Med 366: 1382-1392.

27. Ledermann J, Harter P, Gourley C, Friedlander M, Vergote I, et al. (2014) Olaparib maintenance therapy in patients with platinum sensitive relapsed serous ovarian cancer: A pre-planned retrospective analysis of outcomes by BRCA status in a randomised phase 2 trial. Lancet Oncol 15: 852-861.

28. Matulonis UA, Harter P, Gourley C, Friedlander M, Vergote I, et al. (2016) Olaparib maintenance therapy in patients with platinum-sensitive, relapsed serous ovarian cancer and a BRCA mutation: Overall survival adjusted for post progression poly(adenosine diphosphate ribose) polymerase inhibitor therapy. Cancer 122: 1844-1852.

29. Pujade-Lauraine E, Ledermann JA, Selle F, Gebski V, Penson RT, et al. (2017) Olaparib tablets as maintenance therapy in patients with platinum-sensitive relapsed ovarian cancer and a BRCA1/2 mutation (SOLO2/ENGOT-Ov21): A double-blind, randomized, placebo-controlled, phase 3 trial. Lancet Oncol 18: 1274-1284.

30. USA National Library of Medicine (2016) Olaparib maintenance monotherapy in patients with BRCA mutated ovarian cancer following first line platinumbased chemotherapy. SOLO-1 2: 1. 
Citation: Luijten D, Vreeswijk MPG, Boere I, Kroep JR (2018) Current and Future Developments of PARP Inhibitors in the Treatment of Breast and Ovarian Cancer. J Cancer Sci Ther 10: 178-189. doi: 10.4172/1948-5956.1000542

31. USA National Library of Medicine (2016) Olaparib as adjuvant treatment in patients with germline BRCA mutated high risk HER2 negative primary breast cancer. Olympia 2: 1

32. USA National Library of Medicine (2013) Assessment of the efficacy and safety of Olaparib monotherapy versus physician's choice chemotherapy in the treatment of metastatic breast cancer patients with germline BRCA1/2 mutations. Olympiad 2: 1

33. Robson M, Im S, Senkus E, Binghe Xu, Susan M, et al. (2017) Olaparib for metastatic breast cancer in patients with a germline BRCA mutation. $\mathrm{N}$ Engl J Med 377: 523-533.

34. Puhalla S, Beumer JH, Pahuja S, Appleman LJ, Tawbi HAH, et al. (2014) Final results of a phase 1 study of single-agent veliparib in patient with eithe BRCA1/2-mutated cancer, platinum-refractory ovarian, or basal-like breast cancer. J Clin Oncol 32: 2570.

35. Coleman RL, Sill MW, Bell-McGuinn K, Aghajanian C, Gray HJ, et al. (2015) A phase II evaluation of the potent, highly selective PARP inhibitor veliparib in the treatment of persistent or recurrent epithelial ovarian, fallopian tube, or primary peritoneal cancer in patients who carry a germline BRCA1 or BRCA2 mutation - an NRG Oncology/Gynecologic Oncology Group study. Gynecol Oncol 137: 386-391.

36. Sandhu SK, Schelman WR, Wilding G, Moreno V, Baird RD, et al. (2013) The poly (ADP-ribose) polymerase inhibitor niraparib (MK4827) in BRCA mutation carriers and patients with sporadic cancer: a phase 1 dose-escalation trial. Lancet Oncol 14: 882-892.

37. Mirza MR, Monk BJ, Herrstedt J, Oza AM, Mahner S, et al. (2016) Niraparib maintenance therapy in platinum-sensitive, recurrent ovarian cancer. $\mathrm{N}$ Engl J Med 375: 2154-2164.

38. Oza AM, Matulonis UA, Malander S, Sehouli J, Campo JMD, et al. (2017) Quality of life in patients with recurrent ovarian cancer (OC) treated with niraparib: Results from the ENGOT-OV16/NOVA Trial. Ann Oncol 28: 330-354.

39. USA National Library of Medicine (2013) A phase III trial of Niraparib versus physician's choice in HER2 Negative, germline BRCA mutation-positive breast cancer patients (BRAVO) [https://clinicaltrials.gov/ct2/show/NCT01905592].

40. USA National Library of Medicine (2016) A study of Niraparib maintenance treatment in patients with advanced ovarian cancer following response on front-line platinum-based chemotherapy [https://clinicaltrials.gov/ct2/show/ NCT02655016].

41. Kristeleit RS, Burris HA, LoRusso P, Patel MR, Asghar US, et al. (2014) Phase 1/2 study of oral rucaparib: Final phase 1 results. J Clin Oncol. 32: 2573

42. Drew Y, Ledermann J, Hall G, Rea D, Glasspool R, et al. (2016) Phase 2 multicentre trial investigating intermittent and continuous dosing schedules of the poly (ADP-ribose) polymerase inhibitor rucaparib in germline BRCA mutation carriers with advanced ovarian and breast cancer. British Journal of Cancer 114: 723-730.

43. Swisher EM, Lin KK, Oza AM, Scott CL, Giordano H, et al. (2017) Rucaparib in relapsed, platinum-sensitive high grade ovarian carcinoma (ARIEL2 Part 1): An international, multicentre, openlabel, phase 2 trial. Lancet Oncol 18: 75-87.

44. Coleman RL, Oza AM, Lorusso D, Aghajanian C, Oaknin A, et al. (2017) Rucaparib maintenance treatment for recurrent ovarian carcinoma after response to platinum therapy (ARIEL3): A randomized, double-blind, placebocontrolled, phase 3 trial. Lancet 390: 1949-1961.

45. Balmaña J, Tung NM, Isakoff SJ, Graña B, Ryan PD, et al. (2014) Phase trial of olaparib in combination with cisplatin for the treatment of patients with advanced breast, ovarian and other solid tumors. Ann Oncol 25: 1656-1663.

46. Oza AM, Cibula D, Benzaquen AO, Poole C, Mathijssen RJH, et al. (2015) Olaparib combined with chemotherapy for recurrent platinum-sensitive ovarian cancer: A randomised phase 2 trial. Lancet oncology 16: 87-97.

47. Dent RA, Lindeman GJ, Clemons M, Wildiers H, Chan A, et al. (2013) Phase trial of the oral PARP inhibitor olaparib in combination with paclitaxel for first or second-line treatment of patients with metastatic triple-negative breast cancer. Breast Cancer Res 15: R88.

48. Bell-McGuinn KM, Brady WE, Schilder RJ, Fracasso PM, Moore KN, et al. (2015) A phase I study of continuous veliparib in combination with IV carboplatin/paclitaxel or IV/IP paclitaxel/cisplatin and bevacizumab in newly diagnosed patients with previously untreated epithelial ovarian, fallopian tube, or primary peritoneal cancer: An NRG oncology/gynaecologic oncology group study. J Clin Oncol 33: 5507.
49. Kummar S, Oza AM, Fleming GF, Sullivan DM, Gandara DR, et al. (2015) Randomized trial of oral cyclophosphamide and veliparib in high-grade serous ovarian, primary peritoneal, or fallopian tube cancers, or BRCA-mutant ovarian cancer. Clin Cancer Res 21: 1574-1582.

50. Gray HJ, Bell-McGuinn K, Fleming GF, Cristea M, Xiong H, et al. (2018) Phase I combination study of the PARP inhibitor veliparib plus carboplatin and gemcitabine in patients with advanced ovarian cancer and other solid malignancies. Gynecol Oncol 148: 507-514.

51. Mayo Clinic (2015) Veliparib with carboplatin and paclitaxel and as continuation maintenance therapy in subjects with newly diagnosed stage III or IV, highgrade serous, epithelial ovarian, fallopian tube, or primary peritoneal cancer available at https://clinicaltrials.gov/ct2/show/NCT02470585.

52. Loibl S, O'Shaughnessy J, Untch M, Sikov WM, Rugo HS, et al. (2018) Addition of the PARP inhibitor veliparib plus carboplatin or carboplatin alone to standard neoadjuvant chemotherapy in triple negative breast cancer (BrighTNess): A randomised, phase 3 trial. Lancet Oncol 19: 497-509.

53. Rodler ET, Gralow J, Kurland BF, Griffin M, Yeh RF, et al. (2014) Phase I: Veliparib with cisplatin (CP) and vinorelbine (VNR) in advanced triple-negative breast cancer (TNBC) and/or BRCA mutation-associated breast cancer. J Clin Oncol 32: 2569-2569.

54. Isakoff SJ, Overmoyer B, Tung NM, Gelman RS, Giranda VL, et al. (2010) A phase II trial of the PARP inhibitor veliparib (ABT888) and temozolomide for metastatic breast cancer. J Clin Oncol 28: 1019.

55. Somlo G, Frankel PH, Luu TH, Ma C, Arun B, et al. (2013) Efficacy of the combination of ABT-888 (veliparib) and carboplatin in patients with BRCAassociated breast cancer. J Clin Oncol 31: 1024.

56. Wesolowski R, Zhao M, Geyer SM, Lustberg MB, Mrozek E, et al. (2014) Phase I trial of the PARP inhibitor veliparib (V) in combination with carboplatin (C) in metastatic breast cancer (MBC). J Clin Oncol 32: 1074.

57. USA National Library of Medicine (2011) A study of MK-4827 in combination with standard chemotherapy in participants with advanced solid tumors (MK 4827-008 AM1), available at https://clinicaltrials.gov/ct2/show/NCT01110603.

58. USA National Library of Medicine (2010) MK-4827 in combination with pegylated liposomal doxorubicin in participants with advanced solid tumors and ovarian cancer (MK-4827-011) [https://clinicaltrials.gov/ct2/show/NCT01227941].

59. Plummer R, Jones C, Middleton M, Wilson R, Evans J, et al. (2008) Phase study of the poly(ADP-Ribose) polymerase inhibitor, AG014699, in combination with temozolomide in patients with advanced solid tumours. Clin Cancer Res 14: 7917-7923.

60. Mittica G, Genta S, Aglietta M, Valabrega G (2016) Immune checkpoint inhibitors: A new opportunity in the treatment of ovarian cancer. Int J Mol Sci 17: E1169.

61. Birkbak NJ, Kochupurakkal B, Izarzugaza JM, Eklund AC, Li Y, et al. (2013) Tumor mutation burden forecasts outcome in ovarian cancer with BRCA1 or BRCA2 mutations. PLoS One 8: e80023.

62. McAlpine JN, Porter H, Kobel M, Nelson BH, Prentice LM, et al. (2012) BRCA1 and BRCA2 mutations correlate with TP53 abnormalities and presence of immune cell infiltrates in ovarian high-grade serous carcinoma. Mod Pathol 25 : 740-750.

63. Strickland KC, Howitt BE, Shukla SA, Rodig S1, Ritterhouse LL, et al. (2016) Association and prognostic significance of BRCA1/2-mutation status with neoantigen load, number of tumour-infiltrating lymphocytes and expression of PD-1/PD-L1 in high grade serous ovarian cancer. Oncotarget 7: 13587-13598.

64. Jiao S, Xia W, Yamaguchi H, Wei Y, Chen MK, et al. (2017) PARP inhibitor upregulated PD-L1 expression and enhances cancer-associated immunosuppression. Clin Cancer Res 23: 3711-3720.

65. Welsby I, Huntin D, Leo O (2012) Complex roles of members of the ADP ribosyl transferase super family in immune defences: Looking beyond PARP1. Biochem Pharmacol 84: 11-20.

66. Rosado MM, Bennici E, Novelli F, Pioli C (2013) Beyond DNA repair, the immunological role of PARP-1 and its siblings. Immunology 139: 428-437.

67. Higuchi T, Flies DB, Marjon NA, Mantia-Smaldone G, Ronner L, et al. (2015) CTLA-4 blockade synergizes therapeutically with PARP inhibition in BRCA1deficient ovarian cancer. Cancer Immunol Res 3: 1257-1268.

68. Huang J, Wang L, Cong Z, Amoozgar Z, Kiner E, et al. (2015) The PARP1 inhibitor BMN 673 exhibits immunoregulatory effects in a Brca1(-/-) murine model of ovarian cancer. Biochem Biophys res commun 463: 551-556. 
Citation: Luijten D, Vreeswijk MPG, Boere I, Kroep JR (2018) Current and Future Developments of PARP Inhibitors in the Treatment of Breast and Ovarian Cancer. J Cancer Sci Ther 10: 178-189. doi: 10.4172/1948-5956.1000542

69. USA National Library of Medicine (2015) PARP-inhibition and CTLA-4 blockade in BRCA-deficient ovarian cancer [https://clinicaltrials.gov/ct2/show/results/ NCT02571725]. Accessed on July 25, 2018.

70. USA National Library of Medicine (2016) A phase I/II study of MEDI4736 in combination with olaparib in patients with advanced solid tumors [https:// clinicaltrials.gov/ct2/show/NCT02734004]. Accessed on July 25, 2018.

71. USA National Library of Medicine (2016) Olaparib, durvalumab, and tremelimumab in treating patients with recurrent or refractory ovarian, fallopian tube or primary peritoneal cancer with BRCA1 or BRCA2 mutation [https:// clinicaltrials.gov/ct2/show/NCT02953457]

72. Phase I/II study of the anti-programmed death ligand-1 antibody MEDI4736 in combination with olaparib and/or cediranib for advanced solid tumours and advanced or recurrent ovarian, triple negative breast, lung, prostate and colorectal cancers [https://clinicaltrials.gov/ct2/show/NCT02484404]

73. Study of Niraparib in combination with Pembrolizumab (MK-3475) in patients with triple-negative breast cancer or ovarian cancer (TOPACIO) [https:// clinicaltrials.gov/ct2/show/NCT02657889]. Mayo Clinic 2: 1.

74. Bindra RS, Gibson SL, Meng A, Westermark U, Jasin M, et al. (2005) Hypoxia-induced down-regulation of BRCA1 expression by E2Fs. Cancer Res 65:11597-11604

75. Liu JF, Tolaney SM, Birrer M, Fleming GF, Buss MK, et al. (2013) A phase 1 trial of the poly (ADP-ribose) polymerase inhibitor olaparib (AZD2281) in combination with the anti-angiogenic cediranib (AZD2171) in recurrent epithelial ovarian or triple-negative breast cancer. Eur J cancer 49: 2972-2978.

76. Liu JF, Barry WT, Birrer M, Lee JM, Buckanovich RJ, et al. (2014) Combination cediranib and olaparib versus olaparib alone for women with recurrent platinum-sensitive ovarian cancer: A randomised phase 2 study. Lancet Oncol 15: $1207-1214$.

77. Zimmer A, Peer C, Kohn E, Lipkowitz S, Annunziata C, et al. (2017) A phase study of durvalumab (D) in combination with olaparib $(O)$ and cediranib (C) in recurrent women's cancers. Ann Oncol 28: 122-141.

78. Lord CJ, Ashworth A (2013) Mechanisms of resistance to therapies targeting BRCA-mutant cancers. Nat Med 19: 1381-1388.

79. Xu G, Chapman JR, Brandsma I, Yuan J, Mistrik M, et al. (2015) REV7 counteracts DNA double-strand break resection and affects PARP inhibition. Nature 521: 541-544

80. Gupta R, Somyajit K, Narita T, Maskey E, Stanlie A, et al. (2018) DNA repair network analysis reveals shield in as a key regulator of NHEJ and PARP inhibitor sensitivity. Cell 173: 972-988.

81. Chaudhuri AR, Callen E, Ding X, Gogola E, Duarte AA, et al. (2016) Replication fork stability confers chemoresistance in BRCA-deficient cells. Nature 535: 382-387.

82. Sun C, Zhang D, Xiang T, Chen Q, Pandita TK, et al. (2014) Phosphorylation of ribosomal protein S6 confers PARP inhibitor resistance in BRCA1-deficient cancers. Oncotarget 5: 3375-3385.

83. Nakagawa $Y$, Sedukhina AS, Okamoto N, Nagasawa S, Suzuki N, et al (2015) NF-kB signalling mediates acquired resistance after PARP inhibition. Oncotarget 6: 3825-3839.

84. Lord CJ, Ashworth A (2016) BRCAness revisited. Nature 16: 110-120.

85. Larsen MJ, Kruse TA, Tan Q, Lænkholm AV, Bak M, et al. (2013) Classification within molecular subtypes enables identification of BRCA1/BRCA2 mutation carriers by RNA tumour profiling. PLoS ONE 8: e64268.

86. Dacies H, Glodzik D, Morganella S, Yates LR, Staaf J, et al. (2017) HRDetect is a predictor of BRCA1 and BRCA2 deficiency based on mutational signatures. Nat Med 23: 517-525.

87. Alexandrov LB, Nik-Zainal S, Wedge BC, Aparicio SA, Behjati S, et al. (2013) Signatures of mutational processes in human cancer. Nature 500: 415-421.

88. Telli ML, Timms KM, Reid J, Hennessy B, Mills GB, et al. (2016) Homologous recombination deficiency (HRD) score predicts response to platinum-containing neoadjuvant chemotherapy in patients with triple-negative breast cancer. Clin cancer res 22: 3764-3773.

89. Mukhopadhyah A, Plummer ER, Elattar A, Soohoo S, Uzir B, et al. (2012) Clinicopathological features of homologous recombination- deficient epithelia ovarian cancers: Sensitivity to PARP inhibitors, platinum and survival. Cancer Res 72: 5675-5682.
90. Gelmon KA, Tischkowitz M, Mackay H, Swenerton K, Robidoux A, et al. (2011) Olaparib in patients with recurrent high-grade serous or poorly differentiated ovarian carcinoma or triple-negative breast cancer: A phase 2, multicentre, open-label, non-randomised study. Lancet Oncol 12: 852-861.

91. De Bono JS, Mina LA, Gonzalez M, Curtin NJ, Wang E, et al. (2013) First-inhuman trial of novel oral PARP inhibitor BMN 673 in patients with solid tumours. J Clin Oncol 15: 2580.

92. USA National Library of Medicine (2013) Olaparib treatment in BRCA mutated ovarian cancer patients after complete or partial response to platinum chemotherapy [https://clinicaltrials.gov/show/NCT01874353].

93. USA National Library of Medicine (2010) Study to compare the efficacy and safety of olaparib when given in combination with carboplatin and paclitaxel compared with carboplatin and paclitaxel in patients with advanced ovarian cancer [https://clinicaltrials.gov/ct2/show/NCT01081951].

94. USA National Library of Medicine (2011) AZD2281 plus carboplatin to treat breast and ovarian cancer [https://clinicaltrials.gov/ct2/show/study/ NCT01445418].

95. USA National Library of Medicine (2015) Phase I of carboplatin-Olaparib followed by Olaparib monotherapy in advanced cancer (REVIVAL) [https://clinicaltrials. gov/ct2/show/NCT02418624]. Accessed on July 25, 2018.

96. USA National Library of Medicine (2015) A Phase I, open-label, 2-part multicentre study to assess the safety and efficacy of Olaparib in combination with carboplatin in patients with advanced HER-2 negative breast cancer [https://clinicaltrials.gov/ct2/show/NCT02561832].

97. USA National Library of Medicine (2008) Phase I/II study of AZD2281 given in combination with paclitaxel in metastatic triple negative breast cancer, available at https://clinicaltrials.gov/ct2/show/NCT00707707.

98. USA National Library of Medicine (2008) Phase I AZD2281/Cisplatin in advanced solid tumour patients, available at https://clinicaltrials.gov/ct2/show/ NCT00782574.

99. USA National Library of Medicine (2007) Study to assess the safety and tolerability of a PARP inhibitor in combination with carboplatin and/or paclitaxel, available at https://clinicaltrials.gov/ct2/show/NCT00516724.

100.USA National Library of Medicine (2011) Veliparib monotherapy for relapsed ovarian cancer with BRCA mutation, available at https://clinicaltrials. gov/ct2/show/NCT01472783.

101.USA National Library of Medicine (2012) Veliparib and topotecan for relapsed ovarian cancer with negative or unknown BRCA status, available at https://clinicaltrials.gov/ct2/show/NCT01690598.

102. USA National Library of Medicine (2012) The study evaluating efficacy and tolerability of veliparib in combination with temozolomide or in combination with carboplatin and paclitaxel versus placebo in subjects with BRCA1 and BRCA2 mutation and metastatic breast cancer, availble at https://clinicaltrials. gov/ct2/show/NCT01506609.

103. USA National Library of Medicine (2014) A phase 3 randomized, placebocontrolled trial of carboplatin and paclitaxel with or without Veliparib (ABT888) in HER2-negative metastatic or locally advanced unresectable BRCA-associated breast cancer [https://clinicaltrials.gov/ct2/show/study/ NCT02163694].

104.https://clinicaltrials.gov/ct2/show/NCT02032277.

105. USA National Library of Medicine (2010) Veliparib with or without carboplatin in treating patients with stage III-IV breast cancer, available at https:// clinicaltrials.gov/ct2/show/NCT01149083.

106. USA National Library of Medicine (2016) A feasibility study of niraparib for advanced, BRCA1-like, HER2-negative breast cancer patients [https:/l clinicaltrials.gov/ct2/show/NCT02826512].

107.USA National Library of Medicine (2013) A study of niraparib in patients with ovarian cancer who have received three or four previous chemotherapy regimens (QUADRA) [https://clinicaltrials.gov/ct2/show/NCT02354586] Accessed on July 25, 2018.

108. USA National Library of Medicine (2015) ARIEL4: A study of rucaparib versus chemotherapy BRCA mutant ovarian, fallopian tube, or primary peritoneal cancer patients [https://clinicaltrials.gov/ct2/show/NCT02855944]. Accessed on July $25,2018$.

109.USA National Library of Medicine (2011) A study of oral rucaparib in patients with a solid tumor (Phase I) or with gBRCA mutation ovarian cancer (Phase II) [https://clinicaltrials.gov/ct2/show/NCT01482715]. Accessed on July 25, 2018. 
Citation: Luijten D, Vreeswijk MPG, Boere I, Kroep JR (2018) Current and Future Developments of PARP Inhibitors in the Treatment of Breast and Ovarian Cancer. J Cancer Sci Ther 10: 178-189. doi: 10.4172/1948-5956.1000542

110. USA National Library of Medicine (2010) PARP inhibition for triple negative breast cancer (ER-/PR-/HER2-) with BRCA1/2 mutations. [https://clinicaltrials. gov/ct2/show/NCT01074970]. Accessed on July 25, 2018.

111. USA National Library of Medicine (2010) A Study evaluating talazoparib (BMN 673), a PARP inhibitor, in advanced and/or metastatic breast cancer patients with BRCA mutation (EMBRACA Study) (EMBRACA) [https://clinicaltrials.gov/ ct2/show/NCT01945775]. Accessed on July 25, 2018.

112. USA National Library of Medicine (2014) A phase 2, 2-stage, 2-cohort study of Talazoparib (BMN 673), in locally advanced and/or metastatic breast cancer patients with BRCA mutation (ABRAZO Study) (ABRAZO) [https://clinicaltrials. gov/ct2/show/NCT02034916]. Accessed on July 25, 2018.

113. USA National Library of Medicine (2014) Neoadjuvant Talazoparib for patients with a BRCA deleterious mutation[https://clinicaltrials.gov/ct2/show/ NCT02282345]. Accessed on July 25, 2018.

114. USA National Library of Medicine (2015) Talazoparib beyond BRCA (TBB) trial [https://clinicaltrials.gov/ct2/show/NCT02401347]. Accessed on July 25, 2018.

115. USA National Library of Medicine (2016) A study evaluating Talazoparib in relapsed ovarian, fallopian tube, and peritoneal cancer [https://clinicaltrials. gov/ct2/show/NCT02836028]. Accessed on July 25, 2018.

116. USA National Library of Medicine (2015) Olaparib and cediranib maleate in treating patients with recurrent ovarian, primary peritoneal, or fallopian tube cancer [https://clinicaltrials.gov/ct2/show/study/NCT02345265]. Accessed on July 25, 2018.
117. USA National Library of Medicine (2010) Cediranib maleate and olaparib in treating patients with recurrent ovarian, fallopian tube, or peritoneal cancer or recurrent triple-negative breast cancer [https://clinicaltrials.gov/ct2/show/ NCT01116648]. Accessed on July 25, 2018.

118. USA National Library of Medicine (2015) Niraparib and/or niraparibbevacizumab combination against bevacizumab alone in HRD platinum sensitive ovarian cancer (AVANOVA) [https://clinicaltrials.gov/ct2/show/ NCT02354131]. Accessed on July 25, 2018.

119. USA National Library of Medicine (2015) A phase 2 study of cediranib in combination with olaparib in advanced solid tumors [https://clinicaltrials.gov/ ct2/show/NCT02498613]. Accessed on July 25, 2018.

120.USA National Library of Medicine (2017) Study evaluating the efficacy of maintenance Olaparib and Cediranib or Olaparib alone in ovarian cancer patients (ICON9) [https://clinicaltrials.gov/ct2/show/NCT03278717]. Accessed on July 25, 2018.

121. USA National Library of Medicine (2014) Olaparib or Cediranib Maleate and Olaparib compared with standard platinum-based chemotherapy in treating patients with recurrent platinum-sensitive ovarian, fallopian tube, or primary peritoneal cancer [https://clinicaltrials.gov/ct2/show/NCT02446600]. Accessed on July $25,2018$.

122. USA National Library of Medicine (2015) Platine, Avastin and OLAparib in 1st line (PAOLA-1) [https://clinicaltrials.gov/show/NCT02477644]. Accessed on July 25, 2018. 